\section{Storage and retrieval in a paired-associate task*}

\author{
GEORGE MANDLER \\ University of California, San Diego, La Jolla, Calif. 92037
}

Ss were presented with uni- and bidirectional paired-associate tasks under conditions where they determined both storage and retrieval times. Storage time varies with list but not with item difficulty. Retrieval time of correct responses is independent of both list and item difficulty; retrieval times that are unsuccessful vary with item difficulty.

Paired-associate and serial tasks have usually been presented with E-determined exposure times of items. Partly in response to the total time hypothesis (Cooper \& Pantle, 1967), some studies have allowed Ss to determine study or recall time (e.g., Le $\mathrm{Ny}, 1969$; Le $\mathrm{Ny} \&$ Denhière, 1970; Zacks, 1969) and have shown longer study stimes for difficult items. S-determined timing affords the opportunity to look separately at different processing times. Thus, the paired-associate task, using the anticipation method, may be used to assess the amount of time Ss spend in storage and retrieval. Specifically, consider the paired-associate (PA) task as consisting of sets of $A$ and $B$ items with A-B pairs to be learned. When $A$ is presented alone until such time that $S$ chooses to inspect $B$, the time elapsed may be considered as retrieval time-either of the actual time until B is given or until $S$ decides that he cannot retrieve $B$. Once $A$ and $B$ appear together, the amount of study time $S$ chooses may in turn be considered storage time of the A-B pair. Thus, in contrast to studies using fixed $A$ and $A-B$ times, the present study permitted Ss to select the length of time that each of these two events was exposed.

\section{DESIGN}

Two groups of Ss were tested. One group was given two unidirectional PA lists, and the other group was given two bidirectional lists. Two lists were given to all $\mathrm{Ss}$ in order to eliminate early practice effects and to make certain that Ss, by the time they learned the second list, were completely aware of the requirements of the tasks. Only data from the second of the two lists will be reported.

SUBJECTS AND MATERIALS

Twenty undergraduates, fulfilling a course requirement, were assigned at random to the two groups. Two sets of 32 words were used from a pool consisting of mono- and disyllabic

*This research was supported by National Science Foundation Grant GB 20798. nouns with a Thorndike-Lorge (1944) count of AA. Two random pairings of each set of 32 words were prepared, resulting in four different PA lists consisting of 16 pairs each. Two lists, one from each of the two sets of 32 words, were assigned to each $\mathrm{S}$. For each of the PA lists, four different random orders were prepared, and these four trials were repeated three times, for a total of 12 trials per list per $S$.
METHOD AND PROCEDURE

For the unidirectional lists, the $A$ items in Trial 1 remained as $A$ items throughout the task, and similarly for B items. For the bidirectional lists, A items on Trial 1 became $B$ items on Trial 2, reverted to $A$ items on Trial 3 , and so forth. Conversely, the original $B$ item for a particular pair became the A item on every other trial. Thus, the individual pairs were reversed on each trial such that Ss had to anticipate one member of the pair on odd trials and the other member on even trials. A Stowe memory drum was used for the presentation of the lists, with the modification that Ss had two buttons available, one of which presented the A item of a pair and the other of which presented the $A$ and $B$ items together. The buttons also activated a Heathbuilt Servo Recorder (Model EUW-20A), which recorded the time intervals.

Ss were instructed initially in the operation of the memory drum and the two buttons. They were then

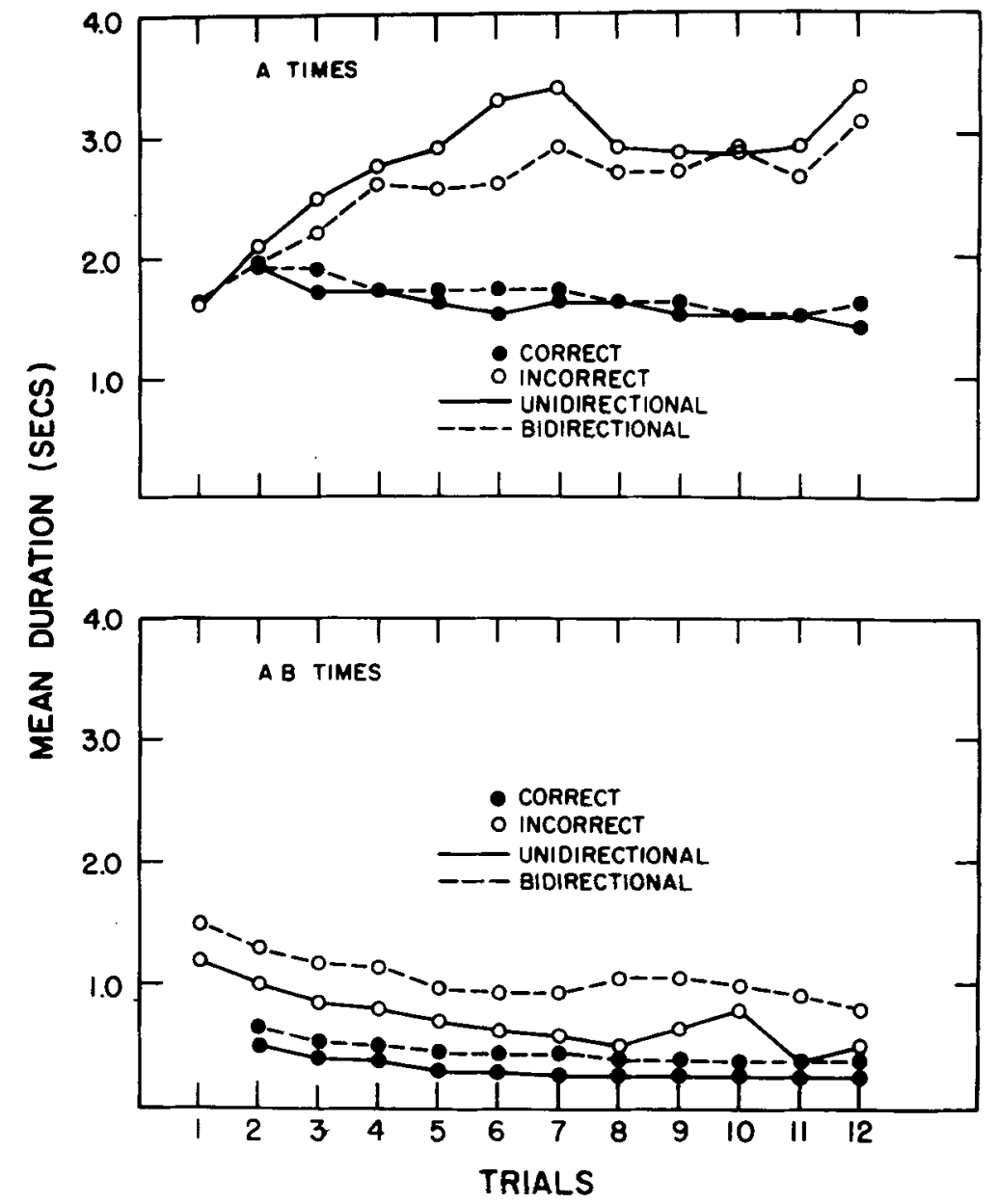

Fig. 1. Mean duration of exposure to $A$ and to A-B items as a function of lists (uni- vs bidirectional) and whether the response to $A$ was correct or incorrect. 
informed about the nature of the PA task and the anticipation procedure. Ss were told to pronounce each item as they saw it. They were told to anticipate the $B$ item as soon as they saw the $A$ item and then to push the appropriate button, but also to proceed, of course, if they could not think of the appropriate $B$ item. They were then given the first list and then, after a pause sufficient to change the tape on the memory drum, were given the second list.

\section{RESULTS}

Mean inspection times for $A$ and A-B items were computed separately for the two groups and separately for pairs on which $\mathbf{S}$ correctly anticipated the $B$ item, and pairs on wh,ch incorrect responses or omissions were given. Figure 1 shows the mean exposure durations in seconds for these four subdivisions. It might be noted that in the analysis of correct vs incorrect instances the number of observations changed, increasing for the correct items and decreasing for the incorrect items. However, by the 12 th trial, the incorrect data still represent some $10 \%-15 \%$ of the observations.

The data for A times show that for correct anticipations there is a very slight decrease in times from just less than 2 sec to approximately $1.5 \mathrm{sec}$ by the 12 th trial. When Ss can retrieve the correct response, the difficulty of the item, i.e., whether it is an item learned late in the task or an item from the more difficult bidirectional list, has little effect on retrieval time. However, for incorrect items, retrieval time, i.e., time spent in attempting to retrieve an item, is a function of difficulty. Retrieval time for both lists increases o ver trials, as presumably more difficult items are being attempted.
Retrieval times for unaccessible items on the more difficult bidirectional list is consistently shorter. One might assume that Ss know that they do not know bidirectional items and, therefore, will go more quickly to the storage phase. It might be noted that even on the first trial Ss spend over $1.5 \mathrm{sec}$ on the A items, when they could not possibly correctly anticipate the correct item. This might be considered an estimate of A study time, trying to store the $A$ item before presentation of the B item. On Trial 2, Ss either know a B item or not, the retrieval times do not differ, and it is only from the third trial on that more time is spent on attempted retrieval.

Storage time shows much less of an effect over time than does retrieval time. B times decline generally and are generally higher when the correct B item was not correctly anticipated. It would be expected that Ss spend more storage time on items they do not know. It is here, too, that we find consistent effects of list differences, and $S s$ spend more time studying pairs for the more difficult bidirectional list. That difference occurs already on Trial 1, since Ss have had prior experience on their first list with the difficulty of the bidirectional task. For correct items, the latency reaches reaction time level very quickly. Ss apparently do not study items that they know.

In summary, it appears that storage time is of relatively short duration-about $1 \mathrm{sec}$ per item-and varies with list difficulty but not with item difficulty since storage times do not increase over trials. Ss seem to respond to the difficulty of the overall task and not to any perceived item difficulty. Item difficulty is reflected in retrieval time, but again probably not because of any decision process by Ss about easy and difficult items but simply because they apparently take longer in fruitless retrieval processes when the final responses are incorrect and the items are difficult to retrieve. Retrieval times for correct items seem to be independent of both item and list difficulty.

A reasonable model for the relational learning that is involved in PA tasks (cf. Mandler, 1970) would need to incorporate a storage process that is influenced by contextual task factors and by immediately preceding retrieval failure, but which is generally of short duration. The retrieval process is of two kinds. Successful retrieval of the kinds of items used here takes about $1.5 \mathrm{sec}$ and is unaffected generally by item or task difficulty. Unsuccessful retrieval varies with item difficulty.

\section{REFERENCES}

COOPER, E. H., \& PANTLE, A. J. The total-time hypothesis in verbal leaming. Psychological Bulletin, 1967, 68, 221-234.

LE NY. J. F. L'effet de position dans un apprentissage intentionnel de série. Année Psychologique, 1969, 69, 81-92.

LE NY J F \& DENHIERE. G L'apprentissage à allure libre de couples associés. Psy chologie Francaise, 1970, 15. 18-29.

MANDLER, G. Words, lists, and categories: An experimental view of organized memory. In J. L. Cowan (Ed.), Studies in thought and language. Tucson: University of Arizona Press, 1970.

THORNDIKE, E L \& LORGE I The teacher's word book of 30,000 words. New York: Bureau of Publications. Teachers College, Columbia University. 1944.

ZACKS, R. T. Invariance of total learning time under different conditions of practice. Journal of Experimental Psy chology, 1969, 82, 441-447. 